\title{
Exploring the Impact of a New Intervention to Increase Participation of Frail Older Adults in Meaningful Leisure Activities
}

\author{
V. Provencher, H. Carbonneau, M. Levasseur, V. Poulin, J. Filiatrault, D. \\ Giroux \& M. Filion-Trudeau
}

To cite this article: V. Provencher, H. Carbonneau, M. Levasseur, V. Poulin, J. Filiatrault, D. Giroux \& M. Filion-Trudeau (2017): Exploring the Impact of a New Intervention to Increase Participation of Frail Older Adults in Meaningful Leisure Activities, Activities, Adaptation \& Aging, DOI: $10.1080 / 01924788.2017 .1376176$

To link to this article: http://dx.doi.org/10.1080/01924788.2017.1376176

曲 Published online: 17 Oct 2017.

Submit your article to this journal

Цll Article views: 10

View related articles

View Crossmark data $\nearrow$ 


\title{
Exploring the Impact of a New Intervention to Increase Participation of Frail Older Adults in Meaningful Leisure Activities
}

\author{
V. Provencher ${ }^{\mathrm{a}, \mathrm{b}}$, H. Carbonneau ${ }^{\mathrm{c}}$, M. Levasseur ${ }^{\mathrm{a}, \mathrm{b}}$, V. Poulin ${ }^{\mathrm{d}}$, J. Filiatrault ${ }^{\mathrm{e}, \mathrm{f}}$, \\ D. Giroux ${ }^{g, h}$, and M. Filion-Trudeau ${ }^{g}$
}

aFaculty of Medicine and Health Sciences, School of Rehabilitation, Université de Sherbrooke, Sherbrooke, QC, Canada; ${ }^{b}$ Centre de recherche sur le vieillissement, Sherbrooke, Trois-Rivières, QC, Canada; 'Department of Studies in Leisure, Culture and Tourism, Université du Québec à Trois-Rivières, QC, Canada; ${ }^{\mathrm{d} C e n t r e ~ i n t e r d i s c i p l i n a i r e ~ d e ~ r e c h e r c h e ~ e n ~ r e ́ a d a p t a t i o n ~ e t ~ i n t e ́ g r a t i o n ~ s o c i a l e, ~ Q u e ́ b e c ~ C i t y, ~ Q C, ~ C a n a d a ; ~}$ eFaculty of Medicine, Department of Rehabilitation, Université de Montréal, Montrèal, QC, Canada; ' $C$ Centre de recherche de l'Institut universitaire de gériatrie de Montréal, Montrèal, QC, Canada; ${ }^{9}$ Faculty of Medicine,

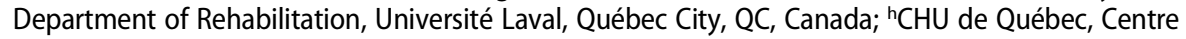
d'excellence sur le vieillissement, Quèbec City, QC, Canada

\begin{abstract}
Many frail older adults have difficulty maintaining social participation. We developed an innovative, personalized intervention to help frail older adults pursue meaningful leisure activities through the use of compensatory strategies. This pre-experimental pilot study conducted with 10 community-dwelling frail older adults ( $\geq 80$ years) showed that the intervention improved their knowledge regarding the compensatory strategies learned and their participation in meaningful leisure activities. However, results also showed a decrease in feelings of well-being. This study provides promising results to support the implementation of an innovative intervention tailored to the needs of frail seniors and designed to foster their participation. However, further research is needed to improve our understanding of the impact of the intervention on well-being and explain the results obtained.
\end{abstract}

\section{ARTICLE HISTORY}

Received 6 April 2016

Accepted 23 August 2017

\section{KEYWORDS}

Compensatory strategies; frail older adults; leisure

\section{Introduction}

In North America, the number of people aged 80 years and older will grow significantly in the next decade (Statistics Canada, 2012; Vincent \& Velkoff, 2010). Such an increase in this segment of the population will be accompanied by a higher prevalence of frailty, which is estimated to be as much as $40 \%$ in the oldest old (Song, Mitnitski, \& Rockwood, 2010). Frailty is characterized by a decrease in the physiological reserves available to the individual, making the person more vulnerable and at increased risk of disability (Bergman et al., 2007). Signs of physical frailty, such as a decrease in walking speed and grip strength, can greatly limit the participation of frail seniors in meaningful activities, including leisure

CONTACT V. Provencher Veronique.Provencher@USherbrooke.ca $\theta$ Université de Sherbrooke, 3001, 12e Avenue Nord, Sherbrooke, QC, Canada J1H 5N4

Color versions of one or more of the figures in the article can be found online at www.tandfonline.com/waaa. 
(Bonder \& Dal Bello-Haas, 2008; Simone \& Haas, 2013). Other characteristics reported to be associated with frailty, such as low income (Béland et al., 1998) and a poor social network (Lebel, Rodereda, Kergoat, Latour, \& Ducharme, 1999), may further restrict participation and lead the person to abandon these meaningful activities. For example, restrictions in physical functioning may interfere with mobility in the community (e.g., going to church or seniors' community center), while limited financial resources or a poor social network may restrict access to transportation. Participation in leisure decreases with aging (Griffin \& McKenna, 1999; Havens \& Finlayson, 1999), and this abandonment has been reported to be marked among the oldest and frailest (Simone \& Haas, 2013). Restriction in participation is a matter for concern since engagement in meaningful leisure activities helps to improve seniors' well-being (Agahi, Silverstein, \& Parker, 2011; Kleiber, McGuire, Aybar-Damali, \& Norman, 2008; Raymond, Sévigny, \& Tourigny, 2012; Zawadzki, Smyth, \& Costigan, 2015), in addition to making life meaningful and satisfying (Berger, 2010; Griffin \& McKenna, 1999; Minhat \& Mohd Amin, 2012). Fostering participation in meaningful leisure activities is thus important to help older adults maintain an active lifestyle and encourage their social integration (Québec Government, 2004; Simone \& Haas, 2013).

A range of compensatory strategies is available to address barriers associated with disability or environmental factors experienced by this population. These compensatory strategies can be defined as a set of tools used to reduce the impact of barriers that restrict participation in activities (e.g., use of community services) (Robichaud \& Lamarre, 2002; Weiss, Hoenig, \& Fried, 2007). They can be divided into three categories: (1) changing behavior (e.g., only drive when there is no traffic), (2) changing the physical environment or using assistive devices (e.g., magnifying glass to read the newspaper), and (3) using human help or community services (such as paratransit) (Hoenig et al., 2006; Robichaud \& Lamarre, 2002; Weiss et al., 2007). However, it seems that many frail seniors do not use these compensatory strategies, even if they would benefit from them (Jopp \& Smith, 2006; Rose, Gitlin, \& Dennis, 2010). A lack of knowledge has been suggested as an important personal factor that may explain less use of compensatory strategies in this population (Gitlin, Hauck, Winter, Dennis, \& Schulz, 2006; Hutchinson \& Nimrod, 2012; Skymne, Dahlin-Ivanoff, Claesson, \& Eklund, 2012). Thus, to foster their participation in leisure activities and wellbeing, it is essential to inform frail older adults about compensatory strategies that they feel are relevant and applicable in their daily lives and help them learn these strategies. However, our recent comprehensive review showed that no intervention was currently available to specifically address this need among frail seniors (Provencher \& Tanguay-Garneau, 2015).

Given the above, our research team undertook to implement an innovative, personalized intervention to help frail seniors increase their knowledge and use of compensatory strategies in meaningful leisure activities. This intervention is congruent with theoretical foundations according to which increasing 
constraints on participation in leisure activities can lead seniors to focus on activities that are meaningful to them (selection), to optimize the choice of activities (optimization) and to compensate for difficulties (compensation) (Baltes \& Baltes, 1990; Leclerc, 2007). This last step, however, requires adopting new ways of doing things, and this knowledge may be more difficult for frail seniors to acquire if there is no support (Kleiber et al., 2008). The intervention differs from others in that it specifically targets a frail population likely to benefit from the use of compensatory strategies to help overcome their increased vulnerability and disability (Contandriopoulos et al., 1999; Gitlin et al., 2009; Lebel et al., 1999) while focusing on the individual needs expressed by each participant about their participation in leisure activities. Thus, selecting strategies and activities that people consider meaningful can increase their motivation to change their behavior and seek out available services and resources (Miller \& Iris, 2002). The strategies targeted through this intervention are ones that frail older adults do not know well but are motivated to use.

This study is based on the ecological model of aging proposed by Lawton (1982, 1983). In this model, psychological benefits are anticipated for older adults when a balance is achieved between demands from the environment (constraints) and resources available (skills). The proposed model thus leads to the assumption that better knowledge and use of compensatory strategies (reducing environmental constraints and increasing older adults' skills) can have a significant impact on reducing barriers that lead to leisure activities being abandoned, and thus on frail seniors' participation in these activities, which may result in improved well-being. The anticipated effects of the intervention are that using compensatory strategies tailored to the needs of frail seniors can reduce the main barriers to their engagement in meaningful leisure activities. Ultimately, an increase in leisure activity participation should improve the well-being of frail seniors.

This pilot study thus aimed to (1) verify the feasibility of implementing an intervention tailored to frail individuals' needs and (2) explore the impact of this new intervention on frail seniors' (a) knowledge regarding compensatory strategies to help them resume meaningful leisure activities, (b) perceived barriers leading them to abandon these activities, (c) re-involvement in leisure activities, and (d) well-being.

\section{Methods}

\section{Design}

This study involved a pre-experimental design combined with an implementation study. For the pre-experimental study, each participant was assessed 1 week prior to the intervention (T1), and 1 month (T2) and 3 months (T3) post-intervention (see Figure 1). The two post-intervention measures aimed to verify whether or not the impact of the intervention was maintained over time. 


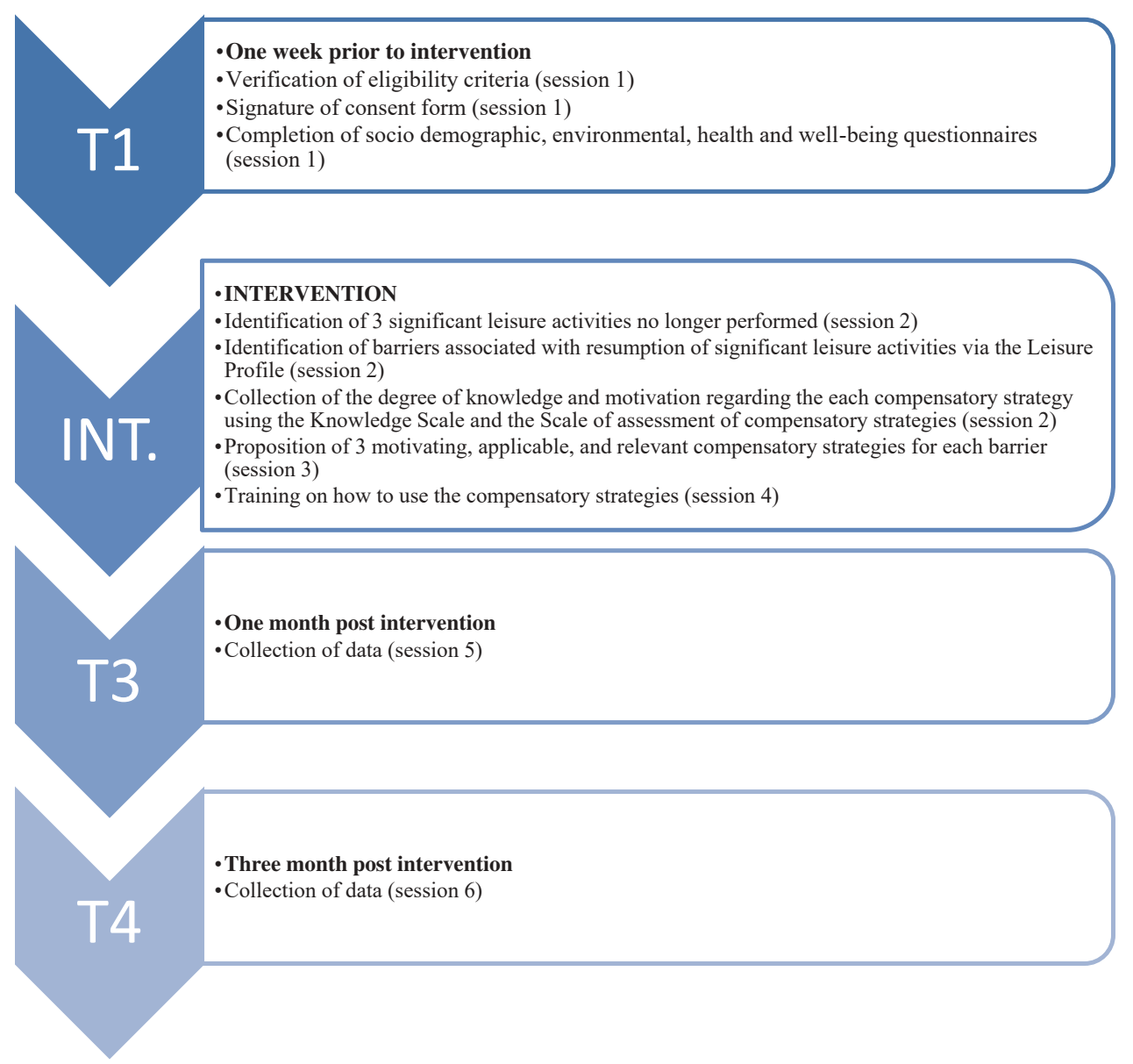

Figure 1. Study design.

\section{Participants}

To be included in this study, participants had to (1) be 80 years of age or older; (2) live in the community (apartment, house, or seniors' residence); (3) meet at least three of the frailty criteria (decreased walking speed, reduced grip strength, low energy, low physical activity, and unintentional weight loss) according to the cutoffs established by Fried et al. (2001); (4) report giving up at least one significant leisure activity in the past year; and (5) be French-speaking (since the intervention was developed in French). People with the following conditions were excluded: (1) signs of possible cognitive impairment (Mini-Mental State Examination <24) (Folstein, Anthony, Parhad, Duffy, \& Gruenberg, 1985) or (2) sensory and language loss that might affect their participation in the tasks required as part of the study (based on clinical judgment). A sample size of 10 participants was targeted since this number is acceptable for pilot studies (Hertzog, 2008). 


\section{Recruitment}

Recruitment was carried out in urban and semi-urban areas of Quebec City (Canada). Participants were recruited from a previous study in which they had consented to be recontacted.

\section{Intervention}

The intervention consisted of three personalized sessions (90 minute duration). First, each participant was asked by a research assistant to identify three meaningful leisure activities that they no longer performed and three barriers to the accomplishment of each meaningful leisure activity (see Leisure Profile, data collection). For each barrier identified, three compensatory strategies were suggested to the participant. Only compensatory strategies that the participant did not know well but was motivated to use were selected (see Scales for Assessment of Compensatory Strategies, data collection). The participant had to consider the proposed strategies to be applicable and relevant. The intervention consisted of teaching the participant how to implement these strategies in his/her daily life. Before meeting, the research assistant contacted the participant by phone to inform him/her about how the learning session would proceed. Then, upon meeting, the research assistant went to the participant's home and helped him/her to implement the compensatory strategy in the context in which the leisure activity was usually performed. For example, if significant fatigue was identified as a barrier to shopping, renting a wheelchair or rollator could be suggested as a useful compensatory strategy. If the participant deemed the strategy to be relevant and applicable, he/she was taught how to rent and use a mobility aid to make it possible to shop or visit a museum, for example, with direct assistance. The anticipated effects of the intervention were based on the assumption that a modest change in how the activity was performed (e.g., using an assistive device) could have a major and significant impact on the daily functioning of frail older adults (Lally \& Crome, 2007). To minimize experimenter bias, the research assistant who administered the intervention (occupational therapy graduate student) was different from the one who assessed the impacts (Contandriopoulos, Champagne, Potvin, Denis, \& Boyle, 2005).

\section{Measures and outcomes}

A questionnaire on demographic, environmental, and health variables was used to collect information on ethnicity, education, income (categorical variable), comorbidities (Hudon, Fortin, \& Vanasse, 2005), depressive symptoms (Bourque, Blanchard, \& Vézina, 1990), vision and hearing loss (Puts, 
Lips, \& Deeg, 2005), perceived social support (Audet, Lemieux, \& Cardin, 2001), architectural barriers (number of interior and exterior stairs), and living environment. This information was gathered in order to describe the variables that may influence the use of compensatory strategies (Ganesh, Fried, Taylor, Pieper, \& Hoenig, 2011; Rose et al., 2010). A logbook was used to collect data pertaining to feasibility issues: (1) unreachable, refusal, exclusion, cancellation, and dropout rates, as well as occurrence of adverse events (e.g., death of proxies, major health change); (2) duration of the intervention session; and (3) difficulties encountered during administration of the intervention.

The Leisure Profile (Profil du loisir) (Carbonneau \& Ouellet, 2003) documented the degree of (1) accomplishment of meaningful leisure activities and (2) perceived importance of the barriers associated with each activity. The frequency of activities performed and the importance of the barriers are reported on a 4-level Likert scale ranging from 0 to 3 (where a higher score indicates more frequent performance of the activity and greater importance of the barriers). This measure has good test-retest reliability and sensitivity to change for the variables measured.

A list of compensatory strategies, based on the work of Robichaud and Lamarre (2002) and of Rose et al. (2010), helped to target appropriate strategies tailored to each participant's needs (see Appendix 1 for examples of compensatory strategies). Two rating scales were used to assess their level of knowledge and motivation concerning the proposed strategies. For the knowledge scale, to the question: "Do you know this strategy?" response choices were (1) I have never heard of this strategy (0 points), (2) I have heard of it (1 point), (3) I know it because I have used it (2 points), or (4) I know it and can explain or show how to use it (3 points). The score (out of 3 points) was computed for each question. The validity (face and content) and reliability (test-retest) of the questionnaire had been verified with professional "experts" $(n=3)$ and a sample of older adults $(n=10)$ before starting this study. Three experts (two clinical occupational therapists with more than 20 years of experience working with seniors and a linguist with a masters in psychoeducation) assessed content validity by independently scoring the level of relevance on a Likert scale (1-irrelevant, 2needs major revision, 3-needs minor revision, 4-relevant) and clarity (1-lack of clarity, 2-needs major revision, 3-needs minor revision, 4-statements clear). Changes were made to incorporate their feedback. Two rounds of revisions were needed to arrive at scores deemed to be valid (a rating of 3 or 4 on each scale) by the three experts. To establish interrater reliability, the degree of agreement between the opinions of three experts (two occupational therapists [OTs]) was tested. Interrater reliability (kappa adjusted for a quadratic weighting) was excellent for the knowledge scale (kappa $=0.90 ; 95 \%$ confidence interval $[\mathrm{CI}]=0.89-0.93)$ and motivation scale $(\mathrm{kappa}=0.97 ; 95 \% \mathrm{CI}=0.95-$ $0.99)$ for the compensatory strategies assessed $(n=215)$. Face validity was 
assessed based on the participants' comprehension and perceived relevance of the statements as well as perceived level of fatigue. A total of $93 \%$ of the components $(n=30)$ received an "Excellent" (A) score.

The General Well-Being Scale (Échelle de bien-être général) (Dupuy, 1978) measures the participant's level of well-being pre- and post-intervention, with higher scores indicating greater well-being (score of $0-60=$ severe distress, $61-72=$ moderate distress, $73-100=$ positive well-being). The French version of the scale (Bravo, Gauvin, \& Dubois, 1996) demonstrated good validity and reliability for older adults.

\section{Data collection}

The study included six data collection sessions (see Figure 1). All sessions took place over a 4-month period. To minimize missing data, questionnaires were administered orally, with visual support featuring oversized characters. Each session lasted approximately 90 minutes and was held at a time chosen by the participant. To minimize bias related to fatigue, breaks in the session were taken when needed. Sessions were held in the participants' homes, to give them a sense of comfort and familiarity. Unreachable, refusal, exclusion, cancellation, and dropout rates as well as occurrence of adverse events (e.g., death of proxies, major health change) were collected throughout the study. Difficulties encountered while administering the intervention were recorded in the logbook after each session. The dependent variables (knowledge concerning strategies, activities, barriers, well-being) were measured (1) 1 week prior to the intervention, (2) 1 month post-intervention, and (3) 3 months post-intervention using the same questionnaires each time (Leisure Profile, Scales Measuring Knowledge and Motivation Concerning Compensatory Strategies, General Well-Being Scale). The evaluations were conducted by a research assistant (occupational therapy graduate student) familiar with the administration of assessment tools and data collection. The research assistant's work was supervised by the principal investigator. The ethics committee of the Centre hospitalier universitaire de Québec approved the study.

\section{Data analyses}

Descriptive analyses were conducted to describe the sample and report feasibility data (unreachable, refusal, exclusion, cancellation, and dropout percentage; duration of intervention session, difficulties encountered during the intervention). The scores for each of the following variables were compared to explore the impact of the intervention on the (1) degree of knowledge concerning the use of compensatory strategies to resume meaningful activities, (2) importance of the barriers associated with each activity, (3) degree of accomplishment of meaningful leisure activities, and (4) well-being. Comparison of the scores before and after the intervention indicated if there was an improvement for each of the outcome 
variables. In view of the type of variables to be analyzed (ordinal), Friedman's test was first used to assess differences between scores (1 week pre-, 1 and 3 months post-intervention) for each variable. When significant differences were detected, the Wilcoxon signed-rank test was used to detect statistically significant changes (pre- vs. post-intervention comparison). The Wilcoxon signed-rank test was also used to assess the stability of the measures collected after the intervention (1 vs. 3 months). Statistical analyses were performed using SPSS.

\section{Results}

As shown in the flowchart (see Figure 2), eight of the 22 eligible participants recruited through a previous study could not be reached. One senior refused

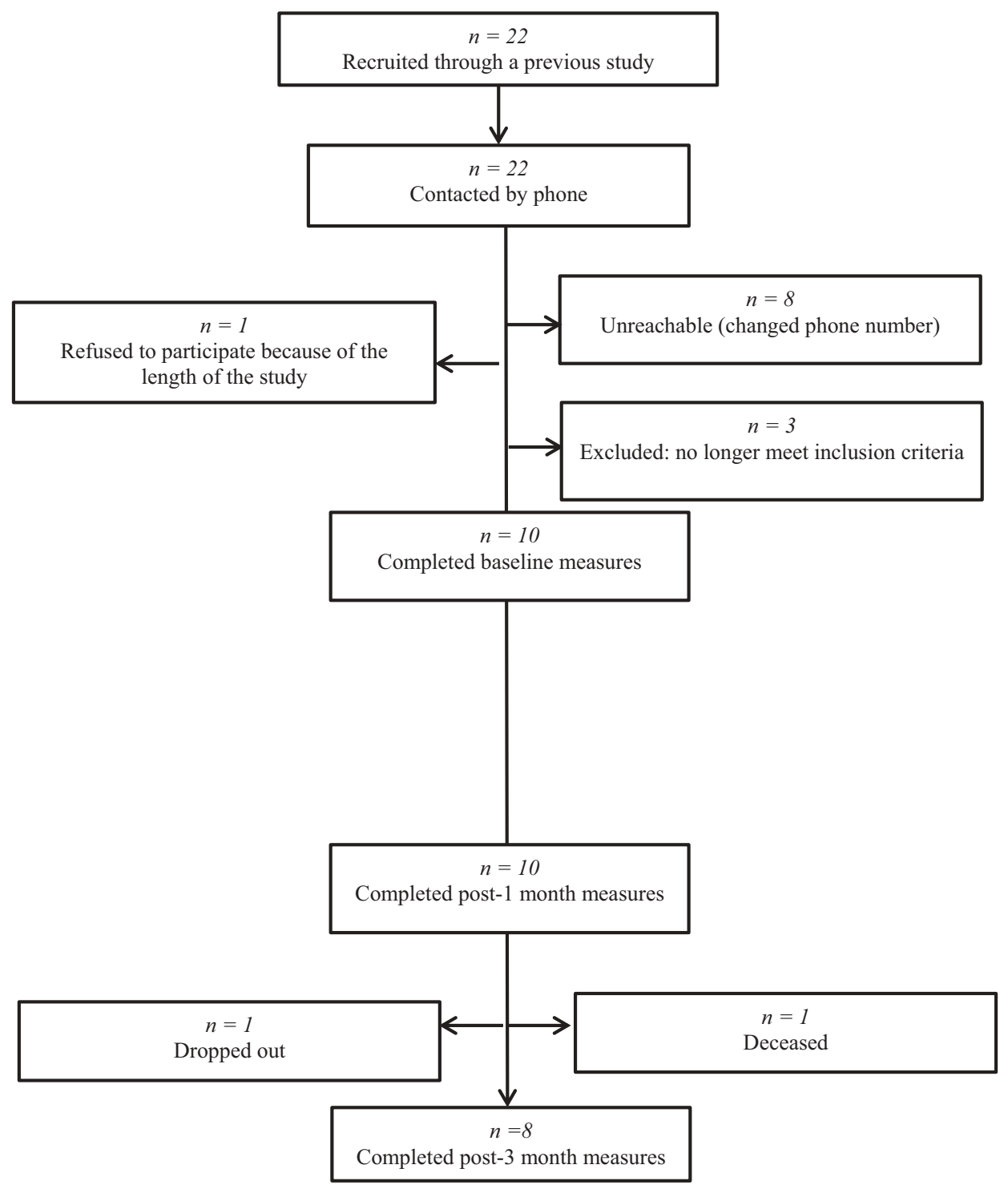

Figure 2. Flowchart of participants' enrollment. 
to participate in the study at baseline while three others were excluded because they did not meet the inclusion frailty criteria. Ten frail older adults completed the intervention and assessment at 1 month post-intervention but one participant dropped out and another died before the 3-month follow-up assessment. Between the baseline and follow-up measures, two participants reported the death of a family member or friend while two others reported health problems requiring medical attention.

Characteristics of the participants $(n=10)$ are presented in Table 1. All participants included in the study at baseline were women; most were over 85 years of age, had completed high school, lived alone, and suffered from arthritis. About one-third of the sample reported a low income. Regarding participants' perception of social support, half of them took part in social activities only once a month and most $(n=7)$ spent their free time alone. Notably, one-third was not satisfied with their social life and reported having no one to talk to.

The average intervention session lasted 73 minutes. Although the strategies suggested were relevant and appropriate to each participant (see Table 2), difficulties encountered during the intervention mainly related to the emergence of new obstacles linked to a first application of the strategies (e.g., unsuspected environmental barriers when using a rollator for the first time). A majority of participants (eight out of 10) still used the strategies they learned 1 month post-intervention while five out of eight participants reported not using them any more at 3 months post-intervention. Following the intervention, participants reported an improvement in knowledge of compensatory strategies as well as increased participation in leisure activities and a reduction in perceived barriers (see Table 3 ). However, when compared to baseline, only the change in the knowledge score at 3 months post-intervention was statistically significant $(p=0.03)$. Surprisingly, a significant decrease in well-being $(p=0.01)$ was observed 3 months postintervention.

\section{Discussion}

The first objective of the study was to verify the feasibility of conducting an innovative intervention tailored to the individual needs of frail older adults. The results from this pilot study indicate that the intervention was feasible to administer. However, descriptive reports suggested that it might be helpful to add another intervention session to provide additional time to learn more complex strategies and find ways to overcome new barriers encountered. A "booster session" could also be included to monitor potential safety issues that arose after the use of the intervention. Challenges remain regarding how to find a way to preserve the applicability of the intervention (not too many sessions) while maintaining its effects. Establishing strong partnerships with 
Table 1. Participants' sociodemographic and health characteristics $(n=10)$.

\begin{tabular}{|c|c|}
\hline Characteristic & $n$ \\
\hline Age $(\mu \pm \sigma)(n=10)$ & $90 \pm 5.2$ \\
\hline \multicolumn{2}{|l|}{ Gender } \\
\hline Male & 0 \\
\hline Female & 10 \\
\hline \multicolumn{2}{|l|}{ Schooling } \\
\hline $1-7$ years & 1 \\
\hline $8-12$ years & 7 \\
\hline 13 years and above & 2 \\
\hline \multicolumn{2}{|l|}{ Income } \\
\hline $10,000-19,999 \$$ & 3 \\
\hline $20,000-39,999 \$$ & 5 \\
\hline $40,000-59,999 \$$ & 1 \\
\hline Refused to say/did not know & 1 \\
\hline \multicolumn{2}{|l|}{ Living environment } \\
\hline Type of residence & 6 \\
\hline House/apartment & 4 \\
\hline Seniors' residence & 8 \\
\hline \multicolumn{2}{|l|}{ Living situation } \\
\hline \multicolumn{2}{|l|}{ Living alone } \\
\hline Geriatric Depression Scale $(\mu \pm \sigma)$ & $8.5 \pm 4.7$ \\
\hline Vision loss-with glasses & 2 \\
\hline Hearing loss & 5 \\
\hline \multicolumn{2}{|l|}{ Current comorbidities } \\
\hline Severe neck or back pain & 3 \\
\hline Arthritis & 7 \\
\hline Serious muscles or tendons problems & 3 \\
\hline Respiratory problems & 2 \\
\hline Metabolic problems & 5 \\
\hline Heart disease & 5 \\
\hline Cancer & 0 \\
\hline Eye diseases that restrict vision & 4 \\
\hline \multicolumn{2}{|l|}{ Perception of social support ${ }^{a}$} \\
\hline \multicolumn{2}{|l|}{ Taking part in social activities } \\
\hline More than once a week & 4 \\
\hline Once a week & 1 \\
\hline Once a month & 5 \\
\hline \multicolumn{2}{|l|}{ Free time } \\
\hline Alone & 7 \\
\hline Mostly alone & 3 \\
\hline Half of the time alone & 1 \\
\hline With someone & 2 \\
\hline \multicolumn{2}{|l|}{ Perception of social life } \\
\hline Mostly satisfied & 7 \\
\hline Mostly unsatisfied & 3 \\
\hline \multicolumn{2}{|l|}{ Having someone to talk to } \\
\hline Has someone & 7 \\
\hline Has no one & 3 \\
\hline
\end{tabular}

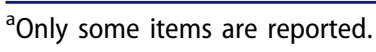

community-based stakeholders promoting leisure activities and delivering health-promoting services to frail older adults would help to strike a balance between the feasibility and effectiveness of such interventions.

The second aim of the study was to explore the impact of this intervention on frail seniors' (a) knowledge regarding compensatory strategies to help 
Table 2. Selected leisure activities, barriers reported, and strategies suggested.

\begin{tabular}{|c|c|c|}
\hline Selected activities & Barriers reported & Strategies suggested \\
\hline Paint & $\begin{array}{l}\text { Difficulty manipulating small } \\
\text { objects }\end{array}$ & $\begin{array}{l}\text { Changing the physical environment/ } \\
\text { Using materials/assistive devices } \\
\text { Magnifier for paint brushes }\end{array}$ \\
\hline \multirow[t]{2}{*}{ Take a walk } & $\begin{array}{l}\text { Strength limited. Get tired or run } \\
\text { out of steam quickly }\end{array}$ & $\begin{array}{l}\text { Changing the physical environment/ } \\
\text { Using materials/assistive devices } \\
\text { Walking aids (rollator) } \\
\text { Changing behavior/Adapting the } \\
\text { activity } \\
\text { Use energy conservation techniques }\end{array}$ \\
\hline & $\begin{array}{l}\text { Do not have enough energy or } \\
\text { interest to get moving and to make } \\
\text { the necessary efforts }\end{array}$ & $\begin{array}{l}\text { Using human help/Community services } \\
\text { Join the residence's walking groups }\end{array}$ \\
\hline Observe nature & $\begin{array}{l}\text { Difficulty getting moving to } \\
\text { perform the activities }\end{array}$ & $\begin{array}{l}\text { Using human help/Community services } \\
\text { Performing the activity with a family } \\
\text { member }\end{array}$ \\
\hline Play Scrabble & $\begin{array}{l}\text { Do not have partners. Has no one } \\
\text { to participate in activities }\end{array}$ & $\begin{array}{l}\text { Using human help/Community services } \\
\text { Participate in a Scrabble game at the } \\
\text { social club }\end{array}$ \\
\hline Use a computer & $\begin{array}{l}\text { Problems with concentration or } \\
\text { memory }\end{array}$ & $\begin{array}{l}\text { Changing the physical environment/ } \\
\text { Using materials/assistive devices } \\
\text { Use of cards containing the steps to } \\
\text { follow }\end{array}$ \\
\hline Read & $\begin{array}{l}\text { Problems with concentration or } \\
\text { memory }\end{array}$ & $\begin{array}{l}\text { Changing behavior/Adapting the } \\
\text { activity } \\
\text { Taking breaks while reading }\end{array}$ \\
\hline Do crosswords & $\begin{array}{l}\text { Difficulty manipulating small } \\
\text { objects }\end{array}$ & $\begin{array}{l}\text { Changing the physical environment/ } \\
\text { Using materials/assistive devices } \\
\text { Magnifiers for pencils }\end{array}$ \\
\hline
\end{tabular}

Table 3. Comparison of pre- and post-intervention scores for outcome measures $(n=8)$.

\begin{tabular}{|c|c|c|c|c|c|c|c|}
\hline & \multicolumn{2}{|c|}{ Time 1} & \multicolumn{2}{|c|}{ Time 2} & \multicolumn{2}{|c|}{ Time 3} & \multirow[b]{2}{*}{$p$-Value ${ }^{a}$} \\
\hline & M & SD & $M$ & SD & $M$ & $\mathrm{SD}$ & \\
\hline Knowledge $^{\mathrm{b}}(/ 3)$ & 1.13 & 1.13 & 1.88 & 0.99 & 2.25 & 0.46 & $0.04^{*}$ \\
\hline Activities (/3) & 0.13 & 0.35 & 0.38 & 0.52 & 0.88 & 1.13 & 0.08 \\
\hline Barriers (/3) & 2.38 & 0.74 & 1.75 & 1.28 & 2.13 & 0.99 & 0.63 \\
\hline Well-being $^{c}(/ 100)$ & 81.40 & 15.33 & 70.10 & 16.29 & 66.50 & 19.41 & $<0.01^{*}$ \\
\hline
\end{tabular}

M: Mean; SD: standard deviation.

${ }^{\mathrm{a}}$ Friedman test.

${ }^{\mathrm{b}}$ Higher scores indicate higher knowledge level.

'Lower scores indicate lower well-being on the Scale of general well-being.

* Significant difference $(p<0.05)$ between the pre-intervention and 3 months post-intervention scores (according to Wilcoxon signed-rank test).

them resume meaningful leisure activities that they no longer perform, (b) barriers leading them to abandon these activities, (c) re-involvement in leisure activities, and (d) well-being. The positive impact of the intervention on improved knowledge is in line with a recent study by Levasseur et al. (2015) showing an increase in older adults' knowledge about compensatory 
strategies (e.g., avoid busy highways) for safe and responsible driving following an educational intervention, although the improvement reported in that study was modest. While our results should be interpreted with caution due the exploratory nature of our data, findings from this pilot study generally support the learning of specific compensatory strategies as a modifiable factor that may be targeted in health promotion interventions to foster leisure activities. However, based on descriptive reports, less than half the participants were still using the strategies learned 3 months later. The perceived complexity of the strategies learned (e.g., how to maneuver and overcome obstacles when using a walker in their home environment) may partly explain this result. This interpretation is consistent with results from a qualitative study by Häggblom-Kronlöf, Hultberg, Ericksson, and Sonn (2007) with 10 oldest old adults, which found that strategies that required learning a new way to perform a task were used less by the participants because they thought they were too cognitively demanding. Increased knowledge may also mean experiencing unpleasant feelings or other adverse outcomes when using the strategy (such as increased fatigue or anxiety, stigmatization, dependence on others), which may explain why frail older adults let the strategy drop after the intervention (Häggblom-Kronlöf et al., 2007; Resnick, Allen, Isenstadt, Wasserman, \& Lezzoni, 2009). Frail older adults may unconsciously engage in a cost-benefit analysis (analyzing pros and cons) to decide if they are going to use the strategies they learned or not. This hypothesis is in line with Prochaska's transtheoretical model about behavioral change. Based on this model (Prochaska \& Velicer, 1997), individuals go through the following five stages: precontemplation (unaware of needing to change), contemplation (aware that behaviors need to change), preparation (deciding to change), action (actively engaged in changing behavior), and maintenance (continue to engage in new behaviors). According to this model, the "maintenance" stage is often followed by a "relapse" stage (return to previous behavior), suggesting the importance of adding a "booster session" to the design to support use of the strategies over the long term. Further analysis of the barriers encountered while using the recommended compensatory strategies will help identify ways to improve the effectiveness of such an intervention when applied to the very old.

According to the ecological model of aging proposed by Lawton $(1982,1983)$, we initially hypothesized that better knowledge and use of compensatory strategies would have a significant impact on reducing barriers to frail seniors' participation in meaningful leisure activities and on resuming these leisure activities, which may ultimately result in improved well-being. This assumption was partly supported by our results. Although an increase in participation in meaningful leisure activities was noted, the impact of the intervention on lessening barriers was modest. More surprisingly, a significant decrease in well-being scores between pre- and post-measures was found following the 
intervention. These results contrast with the results of a cross-sectional study by Janke, Son, and Payne (2009) showing that older adults with arthritis who used more compensatory strategies to perform leisure activities reported overall higher levels of well-being. Two theoretical perspectives (hedonic and eudaimonic) may help understand the unexpected decrease in well-being scores (Delle Fave, Massimini, \& Bassi, 2011). Based on the hedonic view, happiness comes from pleasure, comfort, and enjoyment. In contrast, according to the eudaimonic view, happiness is created by the human ability to pursue goals that are meaningful to the individual. If hedonism contributes to happiness, achieving eudaimonia through optimal experience is crucial for well-being (Delle Fave et al., 2011). We can thus hypothesize that many of our participants embraced the eudaimonic view, expecting to reach past levels of performance when engaging in their meaningful leisure activities. However, they might have found themselves unable to "perform" as well as before or were not satisfied with their actual performance, as they were confronted with their increased disability. Targeting a different activity based on leisure interests instead of finding new ways to perform previous leisure activities (e.g., painting with a grip brush) may avoid comparison with such standards (Montgomery, Booth, \& Hutchinson, 2009). Further research including qualitative interviews could help to verify this hypothesis and provide new insight into the reasons for a decrease in well-being in our sample.

Although these results suggest potential positive effects of the intervention we developed, the study has some limitations. First, despite inherent difficulties pertaining to the recruitment and retention of frail older adults (Provencher, Mortenson, Tanguay-Garneau, Bélanger, \& Dagenais, 2014) and an acceptable size for a pilot study, the use of a small convenience sample reduced the external validity of our results. Even if the benefits of the intervention cannot thus be inferred at this stage to the oldest old frail population, our preliminary results are promising enough to warrant further research using a larger sample with more focus on how the intervention can lead to behavior changes and improved well-being. Second, factors external to the intervention may have affected the internal validity of the results. On the one hand, the occurrence of adverse events such as the death of proxies and health problems that required medical attention was reported by half the sample, which could explain the lack of improvement in well-being scores after the intervention. On the other hand, the potential influence of social desirability on knowledge measures and resuming activities could not be excluded. Future research should add a control group to confirm the impact of the intervention. Third, some of the selected strategies were rated at baseline as already known but never used, which could mean that the impact of the intervention on knowledge may be underestimated. These strategies were targeted for intervention because participants said they were not confident using them, even though they had heard about them in the past. Based 
on Bandura's (1982) theory of self-efficacy, successful performance is rooted in beliefs concerning competency and efficacy. Measures of self-efficacy should thus be included in a future study of the intervention to provide further insights into the impact of the intervention.

\section{Conclusion}

This pilot study generated preliminary data to support the implementation of an innovative leisure intervention, which was found to be applicable and suited to the needs of this vulnerable aged population. Even though the intervention yielded promising results about increased knowledge regarding the compensatory strategies learned, a larger scale study with a strong design is needed to improve the internal and external validity of the findings. This intervention should help health professionals to foster frail older adults' participation in leisure activities. However, further research is needed to verify the participants' use of the compensatory strategies learned over several months to improve our understanding of the impact of the intervention on well-being and explain the results obtained. Partnerships with community stakeholders need to be established to implement this promising intervention on a larger scale.

\section{Acknowledgments}

The authors wish to thank Modou Sene (statistician), Andrée-Anne Lajoie (research assistant, intervention), Karine Bélanger, Stephanie Stocco, Natasa Obradovic, and Eugénie C. Pinsonnault (research assistant, manuscript editing) as well as the study participants.

\section{Funding}

This study was supported by the Réseau Québécois de Recherche sur le Vieillissement/ Quebec Network for Research on Aging (Interaction and social support axis).

\section{References}

Agahi, N., Silverstein, M., \& Parker, M. G. (2011). Late-life and earlier participation in leisure activities: Their importance for survival among older persons. Activities, Adaptation \& Aging, 35(3), 210-222. doi:10.1080/01924788.2011.596758

Audet, N., Lemieux, M., \& Cardin, J. F. (2001). Enquête sociale et de santé 1998 - Cahier technique et méthodologique: Définition et composition des indices (Vol. 2, pp. 215). [Social and Health Survey 1998-Technical and methodological manual: Index definition and composition, vol. 2]. Montréal, QC: Institut de la statistique du Québec.

Baltes, P. B., \& Baltes, M. M. (1990). Psychological perspectives on successful aging: The model of selective optimization with compensation. In P. B. Baltes, \& M. M. Baltes (Eds.), Successful aging: Perspectives from the behavioral sciences (pp. 1-34). Cambridge, UK: Cambridge University Press. 
Bandura, A. (1982). Self-efficacy mechanism in human agency. American Psychologist, 37(2), 122-147. doi:10.1037/0003-066X.37.2.122

Béland, F., Haldemann, V., Martin, J. P., Bourque, P., Ouellette, P., \& Lavoie, J. P. (1998). Vieillir dans la communauté: Santé et communauté. Groupe de recherche interdisciplinaire en santé, Faculté de médecine: Secteur santé publique. Montréal, QC: Université de Montréal.

Berger, S. (2010). The meaning of leisure for older adults living with vision loss. Occupation, Participation and Health, 31, 193-199. doi:10.3928/15394492-20101222-01

Bergman, H., Ferrucci, L., Guralnik, J., Hogan, D., Hummel, S., Karunananthan, S., ... Wolson, C. (2007). Frailty: An emerging research and clinical paradigm - Issues and controversies. Journal of Gerontology: Biological Sciences, 62, 731-737.

Bonder, B. R., \& Dal Bello-Haas, V. (2008). Functional performance in older adults (3rd ed.). Philadelphia, PA: F. A. Davis Company.

Bourque, P., Blanchard, L., \& Vézina, J. (1990). Étude psychométrique de l'Échelle de dépression gériatrique [Psychometric study of the geriatric depression scale]. Revue Canadienne Du Vieillissement/Canadian Journal on Aging, 9, 348-355. doi:10.1017/ S0714980800007467

Bravo, G., Gauvin, P., \& Dubois, M.-F. (1996). Validation d'une échelle de bien-être général auprès d'une population âgée de 50 à 75 ans [Validation of a scale of general well-being with a population aged from 50 to 75 years]. Revue Canadienne Du Vieillissement/ Canadian Journal on Aging, 15(1), 112-128. doi:10.1017/S0714980800013325

Carbonneau, H., \& Ouellet, X. (2003). Le Profil individuel en loisir. Développement et modalités d'utilisation [Individual Leisure Profile]. Sherbrooke, Québec, Canada: Centre d'expertise en gérontologie de l'IUGS.

Contandriopoulos, A. P., Champagne, F., Potvin, L., Denis, J., \& Boyle, P. (2005). Savoir préparer une recherche: La définir, la structurer, la financer [How to define, structure, and finance a research proposal]. Montréal, QC: Gaétan Morin Ed.

Contandriopoulos, A.-P., Kergoat, M.-J., Latour, J., Lebel, P., Leduc, N., \& Roberge, D. (1999). L'évaluation de la prise en charge personnes âgées fragiles par les unités de courte durée gériatriques [Assessment of the care management of the frail elderly in geriatric units]. http://www.santecom.qc.ca/BibliothequeVirtuelle/GRIS/2921954338.pdf

Delle Fave, A., Massimini, F., \& Bassi, M. (2011). Psychological selection and optimal experience across cultures: Social empowerment through personal growth. 369 p. ISBN 978-90-4819875-7.

Dupuy, H. J. (1978). Self-representations of general psychological well-being of American adults. Paper presented at the American Public Health Association Meeting, Los Angeles, CA.

Folstein, M., Anthony, J., Parhad, I., Duffy, B., \& Gruenberg, E. M. (1985). The meaning of cognitive impairment in the elderly. Journal of the American Geriatrics Society, 33(4), 228235. doi:10.1111/jgs.1985.33.issue-4

Fried, L. P., Tangen, C. M., Walston, J., Newman, A. B., Hirsh, C., Gottdiener, J., ... McBurnie, M. A. for the Cardiovascular Health Study Collaborative Research Group. (2001). Frailty in older adults: Evidence for a phenotype. Journal of Gerontology: Medical Sciences, 56A, M146-M156.

Ganesh, S. P., Fried, L. P., Taylor, D. H., Jr., Pieper, C. F., \& Hoenig, H. M. (2011). Lower extremity physical performance, self-reported mobility difficulty, and use of compensatory strategies for mobility by elderly women. Archives of Physical Medicine and Rehabilitation, 92, 228-235. doi:10.1016/j.apmr.2010.10.012

Gitlin, L. N., Hauck, W. W., Dennis, M. P., Winter, L., Hodgson, N., \& Schinfeld, S. (2009). Long-term effect on mortality of a home intervention that reduces functional difficulties in 
older adults: Results from a randomized trial. Journal of the American Geriatrics Society, 57 (3), 476-481. doi:10.1111/(ISSN)1532-5415

Gitlin, L. N., Hauck, W. W., Winter, L., Dennis, M. P., \& Schulz, R. (2006). Effect of an inhome occupational and physical therapy intervention on reducing mortality in functionally vulnerable older people: Preliminary findings. Journal of the American Geriatrics Society, 54, 950-955. doi:10.1111/jgs.2006.54.issue-6

Griffin, J., \& McKenna, K. (1999). Influences on leisure and life satisfaction of elderly people. Physical \& Occupational Therapy in Geriatrics, 15(4), 1-16. doi:10.1080/J148V15n04_01

Häggblom-Kronlöf, G., Hultberg, J., Ericksson, B. G., \& Sonn, U. (2007). Experiences of daily occupations at 99 years of age. Scandinavian Journal of Occupational Therapy, 14, 192-200. doi:10.1080/11038120601124448

Havens, B., \& Finlayson, M. (1999). Predictors of successful aging: A twelve-year study of Manitoba elderly. American Journal of Public Health, 81, 63-68.

Hertzog, M. (2008). Considerations in determining sample size for pilot studies. Research in Nursing and Health, 31, 181-190. doi:10.1002/nur.20247

Hoenig, H., Ganesh, S. P., Taylor, D., Pieper, C., Guralnik, J., \& Fried, L. P. (2006). Lower extremity physical performance and use of compensatory strategies for mobility. Journal of the American Geriatrics Society, 54, 262-269. doi:10.1111/jgs.2006.54.issue-2

Hudon, C., Fortin, M., \& Vanasse, A. (2005). Cumulative illness rating scale was a reliable and valid index in a family practice context. Journal of Clinical Epidemiology, 58(6), 603608. doi:10.1016/j.jclinepi.2004.10.017

Hutchinson, S. L., \& Nimrod, G. (2012). Leisure as a resource for successful aging by older adults with chronic health conditions. Journal of Aging and Human Development, 74(1), 41-65. doi:10.2190/AG.74.1.c

Janke, M. C., Son, J. S., \& Payne, L. L. (2009). Self-regulation and adaptation of leisure activities among adults with arthritis. Activities, Adaptation \& Aging, 33(2), 65-80. doi:10.1080/01924780902947058

Jopp, D., \& Smith, J. (2006). Resources and life-management strategies as determinants of successful aging: On the protective effect of selection, optimization, and compensation. Psychological Aging, 21, 253-265. doi:10.1037/0882-7974.21.2.253

Kleiber, D., McGuire, F., Aybar-Damali, B., \& Norman, W. (2008). The paradox of leisure constraints: Having more by doing less. Journal of Leisure Research, 40(3), 343-359.

Lally, F., \& Crome, P. (2007). Undergraduate training in geriatric medicine: Getting it right. Age and Ageing, 36(4), 366-368. doi:10.1093/ageing/afm047

Lawton, M. P. (1982). Competence, environmental press, and the adaptation of older people. In M. P. Lawton, P. G. Windley, \& T. O. Byerts (Eds.), Aging and the environment (pp. 33-59). New York, NY: Springer.

Lawton, M. P. (1983). Environment and other determinants of well-being in older people. The Gerontologist, 23, 349-357. doi:10.1093/geront/23.4.349

Lebel, P., Rodereda, P. B., Kergoat, M. J., Latour, J., \& Ducharme, F. (1999). Le concept de la fragilité selon les personnes âgées [The concept of frailty according to the elderly]. Montréal, QC: Groupe de recherche interdisciplinaire en santé, Faculté de médecine: Secteur santé publique, Université de Montréal.

Leclerc, G. (2007). Le paradoxe du vieillissement réussi [The paradox of successful aging]. In M. Arcand, \& R. Hébert (Eds.), Précis pratique de gériatrie (Chap. 5, 3e ed., pp. 63-82). Paris, France: Edisem et Maloine.

Levasseur, M., Audet, T., Gélinas, I., Bédard, M., Langlais, M.-È., Therrien, F. H., ... D'Amours, M. (2015). Awareness tool for safe and responsible driving (OSCAR): A potential educational intervention for increasing interest, openness and knowledge about 
the abilities required and compensatory strategies among older drivers. Traffic Injury Prevention, 16(6), 578-586. doi:10.1080/15389588.2014.994742

Miller, A. M., \& Iris, M. (2002). Health promotion attitudes and strategies in older adults. Health Education \& Behavior, 29(2), 249-267. doi:10.1177/1090198102029002009

Minhat, S. H., \& Mohd Amin, R. (2012). Sociodemographic determinants of leisure participation among elderly in Malaysia. Journal of Community Health, 37(4), 840-847. doi:10.1007/s10900-011-9518-8

Montgomery, E., Booth, R., \& Hutchinson, S. L. (2009). From a focus on function to rediscovering the self: A case report of an individual with post-stroke depression. Therapeutic Recreation Journal, 43(4), 25-41.

Prochaska, J. O., \& Velicer, W. F. (1997). The transtheoretical model of health behavior change. American Journal of Health Promotion, 12(1), 38-48. doi:10.4278/0890-1171-12.1.38

Provencher, V., Mortenson, B. W., Tanguay-Garneau, L., Bélanger, K., \& Dagenais, M. (2014). Challenges and strategies pertaining to recruitment and retention of frail elderly in research studies: A systematic review. Archives of Gerontology and Geriatrics, 59(1), 1824. doi:10.1016/j.archger.2014.03.006

Provencher, V., \& Tanguay-Garneau, L. (2015). Systematic review performed using following keywords and databases: CINAHL, PsycINFO, Embase, Ageline; (Leisure AND (intervention OR rehabilitation)) OR recreational therapy) AND ((Frail OR Vulnerable) AND older adult)), Restrictions: 1999-2014. French or English, humans. Unpublished manuscript.

Puts, M. T., Lips, P., \& Deeg, D. J. (2005). Sex differences in the risk of frailty for mortality independent of disability and chronic diseases. Journal of the American Geriatrics Society, 53, 40-47. doi:10.1111/j.1532-5415.2005.53008.x

Quebec Government (Gouvernement du Québec). (2004). Un environnement favorable au loisir et à l'activité physique... un atout pour les aînés en résidences [A favorable environment for leisure and physical activity... an asset to seniors in residences]. Retrieved from http://www.kino-quebec.qc.ca/publications/GuideAinesResidence.pdf

Raymond, É., Sévigny, A., \& Tourigny, A. (2012). La participation sociale des aînés: La parole aux aînés et aux intervenants [Social participation: Voices of the elderly and health care providers]. Institut national de santè publique du Quèbec, Institut sur le vieillissement et la participation sociale des aînès de l'Universitè Laval, Direction de santè publique de l'Agence de la santè et des services sociaux de la Capitale-Nationale et Centre 'excellence sur le vieillissement de Québec du Centre hospitalier affilié universitaire de Québec, 53 pages. Retrieved from https://www. inspq.qc.ca/pdf/publications/1466_PartiSocialeAines_ParolesAinesIntervenants.pdf.

Resnick, L., Allen, S., Isenstadt, D., Wasserman, M., \& Lezzoni, L. (2009). Perspectives on use of mobility aids in a diverse population of seniors: Implications for intervention. Disability and Health Journal, 2(2), 77-85. doi:10.1016/j.dhjo.2008.12.002

Robichaud, L., \& Lamarre, C. (2002). Developing an instrument for identifying coping strategies used by the elderly to remain autonomous. American Journal of Physical Medicine \& Rehabilitation, 81, 736-744. doi:10.1097/00002060-200210000-00004

Rose, K. C., Gitlin, L. N., \& Dennis, M. P. (2010). Readiness to use compensatory strategies among older adults with functional difficulties. International Psychogeriatrics, 22, 12251239. doi:10.1017/S1041610210001584

Simone, P. M., \& Haas, A. L. (2013). Frailty, leisure activity and functional status in older adults: Relationship with subjective well-being. Clinical Gerontologist, 36, 275-293. doi:10.1080/07317115.2013.788114

Skymne, C., Dahlin-Ivanoff, S., Claesson, L., \& Eklund, K. (2012). Getting used to assistive devices: Ambivalent experiences by frail elderly persons. Scandinavian Journal of Occupational Therapy, 19(2), 194-203. doi:10.3109/11038128.2011.569757 
Song, X., Mitnitski, A., \& Rockwood, K. (2010). Prevalence and 10-year outcomes of frailty in older adults in relation to deficit accumulation. Journal of the American Geriatrics Society, 58, 681-687. doi:10.1111/j.1532-5415.2010.02764.x

Statistics Canada. (2012). Annual demographic estimates: Canada, provinces and territories http://www.statcan.gc.ca/pub/91-215-x/91-215-x2012000-eng.pdf

Vincent, G. K., \& Velkoff, V. A. (2010). The next four decades: The older population in the United States 2010 to 2050. U.S. Census Bureau, P25-1138. Retrieved from http://www. aoa.acl.gov/aging_statistics/future_growth/DOCS/p25-1138.pdf

Weiss, C. O., Hoenig, H. M., \& Fried, L. P. (2007). Compensatory strategies used by older adults facing mobility disability. Archives of Physical Medicine and Rehabilitation, 88, 1217-1220. doi:10.1016/j.apmr.2007.07.007

Zawadzki, M. J., Smyth, J. M., \& Costigan, H. J. (2015). Real-time associations between engaging in leisure and daily health and well-being. Annals of Behavioral Medicine, 49(4), 605-615. doi:10.1007/s12160-015-9694-3

\section{Appendix 1}

List of compensatory strategies (examples)

Changing behavior or adapting the activity

Changing the time the activity is performed

Using reading techniques

Changing posture while performing the activity

Changing the physical environment or use of materials from the physical environment

Borrowing/buying wheelchair or triportor

Keyboard keyguard

Playing cards holder

Using services offered by the community and help from others

Home delivery service

Paratransit services

Accessible parking permit 